\title{
The First Two Years (2013-2014) of Life: The Excitement of Biology
}

\author{
Jorge A. Santiago-Blay ${ }^{1}$
}

After a record harsh winter in the eastern USA, I am pondering what has happened during the first two years of Life: The Excitement of Biology. Below, I list some of our main accomplishments.

1. Indexing. Life: The Excitement of Biology is now indexed by Google Scholar and its articles continued to be detecteded by Biosis, Biological Abstracts, CAB Abstracts. Other requests for indexing are currently in consideration.

2. Referencing. $\boldsymbol{L E B}$ continues participating fully in CitedBy (CrossRef). The reader may have noticed that many of the references listed in the Literature Cited portion of each paper published on Life: The Excitement of Biology contain a digital object identifier (DOI or doi) link. The DOI is a unique identifying code for a published paper that CrossRef requires its members, such as Blay Publishesrs LLC, to generate. In plain English, every time someone clicks on the digital object identifier (DOI) link of a reference in the digital version of $\boldsymbol{L E} \boldsymbol{B}$, an attempt is made to connect the reader to the cited paper. The process of catapulting the user to the reference of a clicked link is called "resolution" in the lingo of Crossref. Often those "resolutions" are successful and the reader is able to view the desired paper. However, occasionally the link fails to "resolve" to the intended source and, in such cases, it is said that the resolution has failed. Approximately every month, CrossRef sends its members, including Blay Publishers LLC, a summary of the resolutions attempted. I am glad to report that for the last few months, the rate of successful "resolutions" has been $100 \%$.

3. Social Media. Life: The Excitement of Biology continues having a strong digital presence through our new digital carrier, WordPress. I want to thank Ms. Meghan Frost (formerly at Metapress) for all her help during the first 18 months of $\boldsymbol{L E B}$. Meghan has moved into new, life-giving professional endeavors. Also, LEB maintains a regular presence, particularly through Facebook, LinkedIn, and Twitter, among others.

\footnotetext{
${ }^{1} 217$ Wynwood Road, York, Pennsylvania 17402 USA. E-mail: blayjorge@gmail.com
}

DOI: 10.9784/LEB3(1)Santiago-Blay.01

Electronically available on April 18, 2015. Mailed on April 18, 2015. 
4. Responsiveness. Authors, reviewers, subscribers, and members of the boards of Life: The Excitement of Biology continue generously suggesting improvements to the journal many of which we have gratefully incorporated. In spite of the ups and downs in submissions of papers, this editor insists that all scientific papers submitted to $\boldsymbol{L E B}$ be peer-reviewed while reviewers are encouraged to be careful, contructive, and as fast as possible.

These accomplishments could not be possible without the unwavering support of the Courtright Family of York, Pennsylvania, owners of NeFra, "the printers", of the hard copy version as well as the friendly and tremendously helpful staff members of WordPress.

All of this continues helping $\boldsymbol{L E B}$ gain visibility among the communities of scholars. Please, feel free to spread the word about $\boldsymbol{L E} \boldsymbol{B}$ and its high quality, fast publication, and helpfulness; a great value, in sum, science for all. I hope all of you join me in a wonderful voyage of discovery during 2015.

Peace and wellness, sincerely and gratefully,

\section{Jorge Santiago-Blay}

Jorge Santiago-Blay, Ph.D.

Editor-in-Chief, Life: The Excitement of Biology

E-mail: blaypublishers@gmail.com

Facebook: Jorge A. Santiago-Blay

LinkedIn: Jorge Santiago-Blay

Twitter: @blayjorge

Tumblr: Life-The Excitement of Biology

WordPress: Life-The Excitement of Biology 